DOI: 10.2478/rae-2021-0039 Review of Artistic Education no. 222021 310-317

\title{
8. THE EDUCATION AND SOCIAL INTEGRATION OF THE HUMAN INDIVIDUAL
}

\author{
Oana Mariana Ciuchi ${ }^{256}$
}

\begin{abstract}
This paper presents the importance of the action of the educational phenomenon in the formation / development / transformation and social insertion of the human individual. In this sense, we consider the relationship between the development of the human individual (particularly the child) and its formation throughout life. At the same time, within this research approach we will present in detail the role of the schooling stage for becoming a personality able to integrate properly and harmoniously in various environments / social contexts.
\end{abstract}

Key words: education, training, development, schooling, integration, social insertion

\section{Introduction}

An old French saying goes: After bread, education is the most important thing a people needs. If one of the basic needs is food and bread (symbol of the concept of food) largely satisfies this need, the second place in the life of the human being to meet needs is occupied by education. Education is what makes man to be or to become man, in the deepest and most complex sense of the word, that is, it gives him that superiority over all living beings and places him on top of them all. Seen as a specific human activity (Pea, 2004; Banks, J.A.), education is reflected in the society-individual / individual-society relationship, both in the way the individual relates to society, by accepting the social in his life or finding ways to adapt and integrate in this context, but also in society's reaction to the individual, the unique person, with personal characteristics in the context of diversity, in its way of integrating, assimilating the person and making him or her feel accepted and creating favorable conditions in this direction.

Given the practical applicative field of education, it can be stated that education fulfills at least two basic roles in the life of the human being. These roles are outlined by the two defining directions of the process: training and development.The training direction in becoming a human being is explained by the role of education to systematically and intentionally transmit knowledge (Loughran, 2006), principles, values, beliefs in order to accumulate the bases that a person needs for social adaptation. Education, through its formative role, provides the individual with an arsenal of knowledge that he or she needs and that, subsequently, he or she can capitalize on in various contexts, during his or her development.

Through the educational process, the necessary basis is provided for each human individual in the construction of his or her own personality. The acquisition of knowledge, theoretically and, especially, practically, the learning of social values and principles, as well as internalizing the beliefs that guide the human community is the first step in education, because it ensures the training of the

\footnotetext{
${ }^{256}$ Associate Professor PhD., "Petre Andrei” University from Iași, Politehnica University from București, Romania, email: oanapsih@yahoo.com
} 
person, and training is an essential component in achieving education.

The development seen as a direction and, equally, a component of education (Psacharopoulos and Woodhall, 1985) aims, first of all, at the individual potential of the human being that can facilitate the process of adapting the person in society or to the culture of a particular society.

The potential is the result of the acquisition of knowledge, the acquisition of norms, principles, beliefs and values which, taken both together and separately, constitute a basis for individual development. Their capitalization in various life contexts results in life experience, an aspect that conditions the complete and successful adaptation of each human being. The successful adaptation means, in essence, the evolution or development of the person, and the development directly conditions the transformation, thus fulfilling the purpose of education.

Looking around, the daily life experience shows that society has shortcomings in terms of the peaceful relations between individuals, the respect we owe to each other, the ability to provide support or assistance to those in various crisis situations or in other situations in which we see ourselves as deficient and these gaps are often the result of ignorance. Through education, however, these gaps can be removed and replaced with positive aspects that condition an intrapersonal and, at the same time, effective interpersonal development, with lasting implications on the progress of society in general.

Education must be the means by which people acquire the ability to become active participants in their own formation and development for the sake of personal transformation, but also of the society or communities within which they live. In a world characterized by diversity and pluralism, education conditions the learning of values, attitudes and behaviors that allow both children and adults to live together and develop relationships based upon trust and mutual respect.The crucial role of education in ensuring equal opportunities for all people in society, regardless of color, nationality, religion or other criteria by which people can be differentiated is also unanimously recognized. Education is the foundation, the basis on which the human community is built and rebuilt (Bray, 2001).

The core of this construction is represented by the transmission of values and principles from one generation to another, focusing on future generations that ensure the continuity of the human species, responding to the requirements and purpose for which it was created. In an attempt to conclude the role of education in the becoming a human being, we can emphasize the fact that the training conditions the transformation of the human being for its development, to ascend the steps of personal becoming.

\section{The child development in a school context}

The development is defined as a process by which the body and psyche change throughout life (Schipor, D., 2012). This process encompasses a series of both quantitative and qualitative transformations, and is highlighted at the biological, mental and social level. At the biological level, the changes that mark the development of the body are highlighted by physical, biochemical and morphological transformations.The psychic changes are marked by the birth, 
continuity and transformations of psychic processes, functions and characteristics, while the social changes are the result of adapting a person's behavior in accordance with social norms. Consequently, the transformations aimed at the development of the human being have a bio-psychosocial nature.

The development of any human being is conditioned by two types of factors: natural factors - represented byheredity and consists of all the "inheritances" received by the descendants from ascendants and social factors-the environment and the education, which ensure the physical and social framework of the development and effectively lead the persons' development.These factors are closely related (Cronbach, 1969), and the development is the result of the interdependence of these factors, thus ensuring the development of a complex and unitary character.

The educational institutions are the main providers of education, as they provide the institutionalized/formal framework. The functionality of the education system is ensured and regulated by the main legislation (the National Education Law no. 1/2011 and other laws) and the secondary legislation (specific methodologies/regulations/procedures), based upon which the instructiveeducational process is organized and carried out.Thus, the schooling stage of the human individual is the main resource of its development in the cognitive and social plan and the school as an entity becomes the second instance of socialization of the human individual.

In Romania, education is compulsory until the 10th grade and is provided by funding from the state budget. The schooling period includes the age stage between 6/7 years old and 18/19 years old and includes 3 levels of education: primary, lower secondary (middle school) and upper secondary (high school).Each of these levels of education aims to acquire knowledge / skills specific to the age peculiarities of pupils. The school institution is perceived as a source of cognitive development of the person. However, the same formal framework aims at the development of the human being on a physical, mental and social level. Thus, the framework plans are developed to provide children with a complex development. In accordance with the provisions of the National Education Law no. 1/2011, with subsequent amendments and completions, the educational ideal is defined as follows: the free, integral and harmonious development of human individuality, in the formation of autonomous personality and in assuming a system of values that are necessary for personal fulfillment and development, for the development of entrepreneurship, for active citizen participation in society, for social inclusion and for employment on the labor market.

The undeniable role of the school is to cultivate and develop a balanced and harmonious personality of pupils, to help them become fit for social integration, to make decisions autonomously and with full responsibility. Equally and at the same time, the formal education must take into account the training of future adults, by providing a solid value system and applicable conceptions and beliefs about life, for their personal, social and professional life.Developing people with initiative, with a civic spirit, tolerant people who love work, helping them find their role and place in society is a tangible goal if the necessary values are taught to children 
from an early age.

The beginning of schooling highlights the child's socialization, his or her integration into social groups and learning the behaviors and basic rules for the future activity, that of the pupil (Kochanska, 1993). The age of small schooling is characterized by enthusiasm towards the learning activity, towards the assimilation of knowledge, skills and habits, but it can decrease directly proportional to the decrease of the novelty character.Thus, the differences become more and more obvious between those with a fast pace of knowledge assimilation compared to those with a slow pace of knowledge assimilation. Consequently, the intervention of formal education is necessary in order to reduce these discrepancies through the differentiated and personalized treatment of pupils.

The age and individual peculiarities of the child are noticeable in all school activities, and the harmonious mental development is directly conditioned by the abilities to capitalize on them effectively. Their influence is noticeable at the level of all psychic processes, starting from the sensory psychic processes, continuing with the cognitive processes, affective processes and regulatory processes. The young school age brings to the fore a limited baggage of opportunities at the cognitive, physical and psychosocial level, which the pupil possesses, but which represents a good foundation for his or her further development. At this age, therepresentations are diffuse, poorly systematized, but through learning activities they significantly change their scope and content, the way they are produced and how they operate.

The thinking, in the stage of concrete operations, develops its operations: the analysis and synthesis, the comparison, abstraction and generalization, the classification and logical concretization by involvement in learning activities. The child acquires abilities to explain, argue, to reason logically, proving the truth of his judgments.

The language of pupils, quite limited both in number of words and in the areas of coverage for various fields of activity, is becoming richer, increasing the lexical fund, through reading and communication. The ability to express and support one's own ideas through oral or written expression increases by enriching the child's active and passive vocabulary with new words, helping the child to express himself or herself in words adapted to each activity environment.

The memory, which at this age has a small volume, develops by increasing its volume; the learning to read and write and count have a significant contribution to that end. The storage of a larger volume of information will help the pupil to retain data necessary for personal activities and to capitalize on them in various school actions of a formal or non-formal nature.They enable the pupils to structure and restructure the information to be memorized, to replace the unknown with the known, to eliminate unnecessary or insignificant details and to retain and capitalize on the essential and even to add new elements to the memorized content.

The imagination, as a complex cognitive process of elaborating new images and projects, based on the combination and transformation of one's own experiences, closely related to thinking, language and memory, develops in the school context. The learning activities support the expansion of the area of human 
knowledge, help to achieve the process of active, transformative and creative adaptation, and the imagination plays a decisive role in this process. The pupil becomes able to design and organize actions, to detach from the present, characterized by here and now, drawing paths to follow, makes new mental projections and anticipates the results to be obtained. The child's still limited life experience is also reflected in the creative plan, which is characterized by combinations of superficial, spontaneous, often static images, which contain a series of fantastic, inappropriate elements. Learning helps and develops creativity and the narrated or created images acquire abundance, consistency, dynamism and coherence.

The playing and storytelling abilities, the storytelling and composition skills stimulate the creative forms of the young pupil, who, in turn, are supported by activities from all curricular areas.Against the background of the propensity towards learning, towards which the small school child presents certain sensitivity, and in connection with the activity that he or she carries out, the school child's skills develop.By relating to the sphere of affective, motivational and attitudinal processes, conditioned and supported by the child's desire to learn, skills are developed at this age in fields like: mathematics, literature, art, music, as well as the propensity to certain school and extracurricular areas.

The affectivity of the young school child is dependent, on the one hand, on the learning activities themselves, and, on the other hand, on the interpersonal relationships that develop within the school community. Within this framework, the emotions and the intellectual feelings, as well as moral and aesthetic ones, are cultivated and developed. The learning activities should be designed to support the correct understanding and acquisition of the content of notions and norms that underlie the moral feelings. The relating to life experience, to what is practical, applicable will help pupils to understand correctly and capitalize effectively what good and evil, beauty and truth, courage and cowardice, honesty and dishonestymorally mean.

If the predominant form of motivation at this age is extrinsic, in the school context and through learning, the intrinsic motivation is stimulated. The pupil's activity can be supported, in addition to the external motivation, by an internal motivation, which aims to activate the assimilation processes in a continuous way by stimulating and maintaining the child's cognitive curiosity. The desire to learn as much as possible, to grow intellectually, must be maintained, stimulated to meet the needs of knowledge, but also to cultivate the pupils' attachment to school, learning and to keep the interest in the permanent knowledge alive.

From the preschool age, the child's personality is outlined, when some character and temperament traits appear, which later become stable. Simultaneously with the enrollment in schooling, marked by the transition to a new way of life and new forms of activity, the formation of the child's personality continues, which will be influenced by these factors in a decisive way.

The school child status provides major changes in the child's daily activity by facing new requirements, which increase the importance of actions and results obtained by the child at this age. The imprint of school activities on the child's 
personality is strong, both on the internal organization and on the external conduct.

Schooling becomes a framework conducive to the development of personality traits such as: conscientiousness, punctuality, perseverance, the spirit of organization, which are more appreciated and become ways of interpersonal characterization. Pupils learn to approve of the positive character traits, marked by the mentioned character attitudes and to express their disagreement with the character traits considered to be undesirable as: the indifference, the cowardice, the hypocrisy, the negligence, lying and the deception.

The schooling contributes significantly to shaping the profile of the future adult. Through the learning activities, regardless of the framework in which they take place (formal, non-formal or informal) the child / pupil broadens his or her cognitive sphere, an aspect that is reflected in the development of thinking, language, personality, as a whole.This evolution is part of the scope of the educational ideal and corresponds to the needs of the society, which is increasingly in need of people with active principles and values, which are based on fundamental positive values: the good, the truth and the beauty.

\section{The school success and setback}

The school context is an equally favorable field for collaboration, but also for competition, and these conditions often condition the success and well-being in this environment. The school success is a desideratum of any pupil. However, the factors underlying its realization are diverse and to a very small extent concretely defined or rigorously drawn. The school success is described by the two terms, which are in antithesis, but which summarize the level of pupil performance and draw, at the same time, portraits of presentation, but also directions of action.

The success or setback of pupils in exams, the recognition of pupils or their labeling as good pupils or poor pupils unquestionably influences the status of the child in the social groups to which they belong: family, friends, playgroups, etc.The school is labeled or characterized positively or negatively depending on the success or setback of its pupils. Defining the two terms requires a complex analysis of the determinants and a deep knowledge of the pupil's personality. What is certain is that, although in antithesis, the explanation of each term is made by relating to each other, by analogy and comparison.

The relationship between school success and setback is a dynamic, dialectical and complex relationship (Sălăvastru, D., 2004). Setback cannot be definitive and global, just as success does not manifest itself continuously and completely. Both success and setback are considered to be partial; they manifest themselves only in certain segments of activity and are dependent on a complex series of factors that condition their appearance and resilience.

In the description of the level of school performance, the two phrases school success and school setback are sometimes used in antithesis, and, most often, alternatively as they are considered, up to a certain point, to be synonyms (Sălăvăstru, D., 2004, 230 ) - one cannot speak of school setback, as long as the success in this field was not known and, at the same time, the success cannot be defined only by relating its norms to their non-achievement.The notion of school 
setback is the object of study of many researches in the field. The studies dedicated to this topic have highlighted a phenomenon of major complexity, with various presentations and characterizations, of different sizes, difficult to include in a definition.However, the notion of school setback is, on the one hand, more neutral, with a somewhat reduced emotional load and negative psychological impact, and on the other hand, with a more optimistic perspective on rehabilitation opportunities compared to synonymous terms used such as, for example, school failure (which can be attributed to a stronger negative load, taken somewhat to the extreme).

Thus, the school success consists in obtaining a superior efficiency in the instructive-educational activity, at the level of the requirements of the curricula and of the aims of education", and the school setback refers to "lagging behind in learning or not fulfilling the compulsoryrequirementswithin the instructiveeducational processand they are the effect of the discrepancy between exigencies, possibilities and results."(Popescu, 1991, 24; Sălăvăstru, 2012, 231)."From these explanations one can notice that the two terms, which generate facts in the pupil's life are relative, i.e. can only be assessed or judged by reference to other notions that condition them: school rules, requirements of framework plans / programs school, the rules specific to each education system.Consequently, the interpretations given to the phenomena in question may be different, depending on the rules of each educational system, the cultural and educational traditions of the peoples or countries in which they manifest themselves, which have different grading or evaluation systems, differentorganizational structures, degrees of demand and rules to meet.The setback in a particular educational structure does not condition the general school setback, but, often, the rules and rigors according to which the system is guided can lead the same person to compliance and stability or maladaptation and lack of expected results.

\section{Conclusions}

The interpretation of school success or failure is made by reference to the criteria of appreciation and the forms of manifestation. The school setback takes various forms, from the simplest - lagging behind in learning, an aspect that can be easily remedied, if given due attention in time, to severe forms of school dropout or repetition, which are persistent forms, with long-lasting effects and more difficult to fix. Both school success and school setback are delimited by the interpretation of the pupil's school results.

Living in a culture of graded assessments, in which the grading system does not provide the possibility of a complex assessment or an overview of the pupil's potential, certainly the schooling success or setback can often be subjective or irrelevant, assessed and easily diagnosed, but which can have serious consequences for the pupil's further development.

Even if the notions of school success or school setback can be generalized or limited (on some segments of its activity), cognitive (at the level of knowledge assimilation) or non-cognitive (marked by maladaptation to the school environment), episodic or enduring, studies in the field show that before recording 
the pupil's performance as a success or being classified as a setback, it is absolutely necessary to know the pupil and his or her potential, in all forms of manifestation of his or her status as a pupil.By knowing the pupil's potential, one can draw directions in accordance with the educational ideal of his or her learning path.

\section{References}

1. Banks, J. A. (2004). Multicultural education: Historical development, dimensions, and practices. In J. A. Banks \& C. M. Banks (Eds.), Handbook of research in multicultural education (2nd ed., pp. 3-29). San Francisco: Josse

2. Bray, M. (2001). Community Partnerships In Education: Dimensions, Variations And Implications, Background Document prepared for the World Education Forum, Dakar, Senegal, 26-28 April 2000. Paris: UNESCO Publishing

3. Cronbach, L. (1969). Heredity, environment, and educational policy. Harvard Educational Review, 39, 338- 347

4. Kochanska, G. (1993). Toward a synthesis of parental socialization and child temperament in early development of conscience. Child Development, 64, 325347

5. Loughran, J. (2006). Developing a pedagogy of teacher education: Understanding teaching and learning about teaching. London: Routledge

6. Legea educației naționale nr.1/2011, cu modificările și completările ulterioare.

7. Pea, R.D. (2004).The social and technological dimensions of scaffolding and related theoretical concepts for learning, education, and human activity. The Journal of the Learning Sciences, 13, 423-451

8. Popescu V.V. (1991). Succesul şi insuccesul şcolar- precizări terminologice, forme de manifestare, cauze. Revista de pedagogie, nr.12

9. Sălăvăstru, Dorina (2004). Psihologia educației, Editura Polirom, Iași

10. Schipor, Doina Maria. (2012). Psihologia educaţiei, Editura Didactică și Pedagogică, București 